\title{
Management of Perinatal and Infant Oral Health
}

\author{
Saleha Shah ${ }^{1 *}$ and Mubassir Fida ${ }^{2}$ \\ ${ }^{1}$ MCliDent Pediatric Dentistry (UK), BDS Baqai Medical University, Karachi, Pakistan \\ ${ }^{2}$ FCPS Orthodontics, Aga Khan University, Karachi, Pakistan
}

*Corresponding author: Saleha Shah, MCliDent Pediatric Dentistry (UK), BDS Baqai Medical University, Karachi, Pakistan

\begin{abstract}
Mothers in the perinatal stage and infants should be identified and evaluated for the risk of dental caries. Early childhood caries can lead to detrimental consequences in the primary dentition. This entails that oral health care advice regarding oral hygiene, diet, fluoride and dental management be provided to minimize the risk factors and optimize the protective factors to improve the longterm oral health outcomes for both the mother and her infant.
\end{abstract}

Keywords: Perinatal Oral Health; Infant Oral Health; Early Childhood Caries

\section{Introduction}

The perinatal period is vital for the holistic well-being of pregnant women. It is defined as a time span which commences when the 20th to 28th week of gestation is completed and ends at 1 to 4 weeks subsequent to birth of a child [1]. Early childhood caries (ECC) and severe form of ECC (s-ECC) start as soon as teeth start to erupt, develop on every surface of a primary tooth, have a rapid progression with a long-term detrimental impact on the primary dentition [2]. The long term sequelae of ECC include a greater risk of new carious lesions in both the primary and permanent dentitions, $[3,4]$ high cost of treatment, [5] hospital stay and emergency room visits [6,7] loss of school time, [8] diminished cognitive ability [9] and a poor oral health-related quality of life [10]. Hence the oral health of both the mother and the future child are instrumental in preventing and arresting the disease process to manage early childhood caries during this phase [11].

\section{Epidemiology}

This chronic, infectious disease affects the general population however it is 32 times more likely to occur in infants from low socioeconomic status, with high sugar diet and whose mothers have a low education level [12-14] It affects $1-17 \%$ children in developed and $70 \%$ children in under-developed countries [15]. Epidemiologic evidence shows that the highest prevalence of ECC is reported from Africa and South-East Asia [16]. The prevalence of ECC among Indian children between 8-48 months is 44\% [17].
A study from Sri Lanka reports an incidence of 23\% ECC among 1-2-year old's [18]. North American prevalence of ECC ranges from $11-72 \%$ and over $28 \%$ children have caries by the time they reach kindergarten $[19,20]$. Pakistan has a variation in prevalence of ECC ranging $27.9 \%-51 \%[21,22]$.

\section{Anticipatory Guidance According to Caries Risk}

New mothers and infants are seen by the medical health care professionals earlier and more often than dentists. It is therefore important that they understand the dynamic multifactorial etiology and risk factors for ECC prevention counselling in pregnant women/caregivers and encouraging a dental home visit at age 1 [23]. In some instances, pregnant women may defer dental care, experience unwillingness of dentists to provide oral care [24-27] or may be unaware of the implications of poor oral health for their pregnancy $[28,29]$. Hence early identification of mothers with poor oral health/high caries risk and timely delivery of educational information and prevention for themselves and their unborn child can help reduce the incidence of ECC, prevent the need for dental rehabilitation and improve their oral health [30-32]. Caries-risk assessment for infants allows the determination of relative risk for dental disease to prevent disease by identifying and minimizing risk factors (plaque accumulation, diet, lack of topical/systemic fluoride, high frequency of sugar containing medicines) and optimizing protective factors (oral hygiene practices, fluoride and 
fissure sealants) when the primary dentition starts to erupt [33]. The current trend shows more emphasis on prevention and arrest of the disease processes to manage ECC. This is attributed to the costly and high-risk restorative treatment for ECC since it often entails the use of sedation and/or general anesthesia and a high recurrence rate $[34,35]$. The chronic disease management approach encompasses engagement of parents to facilitate preventive measures and temporary restorations of the lesion to defer advanced restorative care [36]. An active surveillance methodology entails monitoring caries progression in children and setting up prevention programs for managing incipient carious lesions [37]. An Interim therapeutic restorations (ITR) is a form of temporary tooth restoration in young children until compliance improves and conventional cavity preparation and restoration is possible [38].

\section{Oral Health Care Advice to Pregnant or Lactating Mothers}

Physicians, dentists, and nurses impart educational advice for mothers during the perinatal period. The preventive advice should include timely brushing with fluoridated toothpastes and use of sugar free gums. The dietary advice should address the quality and quantity of nutritional food along with food cravings that may raise the caries risk. Dental procedures which are considered safe during all trimesters of pregnancy include oral assessment, prophylaxis, local anaesthetic, regular treatment and radiographs with shielding (optimal in second trimester). If, however there is discomfort the elective treatment may be deferred. Breast feeding of infants should be tailored with food over a year or longer but should not be ad libitum. It provides nutritional, developmental and psychological health advantages with a significant decrease in the risk for acute and chronic diseases. It may also transfer maternal medication to infants under 6 months hence use cautiously. It provides awareness of health consequences of tobacco use and exposure to secondhand smoke in children [39-43].

\section{Oral Health Care Advice for Infants}

An infant should be taken for an initial evaluation to a dental home by the age of one by the pediatricians and the general practitioners. This attains the medical and dental history of both the child and parents, allows oral assessment with a demonstration on age appropriate gum and tooth cleaning, brushing the teeth twice a day with an optimum level of fluoridated toothpaste (smear or rice sized for children under 3), dietary advice (avoid sugar by bottle, sippy cup, sugar between meals, 4- 6 ounces of $100 \%$ fruit juice per day for 4-6 year old children, systemically administered fluoride (if the drinking water is unfluoridated) and professional fluoride application if caries risk is high, injury prevention advice for facial trauma (objects, cords, pacifiers, car seats, electric cords), advice on teething with excessive salivation areas of intermittent discomfort (oral analgesics, chilled teething rings, over the counter teething gels), management of atypical frenum attachments (frenectomy or frenuloplasty to facilitate breast feeding) and counselling regarding non-nutritive habits such as digit or pacifier sucking, abnormal tongue thrust or bruxism (wean before skeletal dysplasia or malocclusion) $[33,44,45]$.

\section{Conclusion}

It is very important to design and implement caries assessment in order to identify the caries risk for infants and expectant mothers/lactating mothers. This will allow effective education on oral health via motivational interviewing techniques to help improve oral behaviour and timely implementation of caries preventive measures to help change the trajectory of oral health of a mother and her infant.

\section{References}

1. Brown A (2016) Access for Oral Health Care During the Perinatal Period: A Policy Brief. National Maternal and Child Oral Health Resource Center. Georgetown University Washington DC, USA.

2. Skeie MS, Raadal M, Strand GV, Espelid I (2006) The relationship between caries in the primary dentition at 5 years of age and permanent dentition at 10 years of age - A longitudinal study. Int J Paediatr Dent 16(3): 152-160.

3. Al-Shalan TA, Erickson PR, Hardie NA (1997) Primary incisor decay before age 4 as a risk factor for future dental caries. Pediatr Dent 19(1): 37-41.

4. Ghazal T, Levy SM, Childers NK, Broffitt B, Cutter G et al. (2015) Prevalence and incidence of early childhood caries among African American children in Alabama. J Public Health Dent 75(1): 42-48.

5. Rohde F (2016) Dental Expenditures in the 10 Largest States, 2010 Statistical Brief \#415. June 2013. Agency for Healthcare Research and Quality, Rockville.

6. Ladrillo TE, Hobdell MH, Caviness C (2006) Increasing prevalence of emergency department visits for pediatric dental care 1997-2001. J Am Dent Assoc 137(3): 379-385.

7. Griffin SO, Gooch BF, Beltran E, Sutherland JN, Barsley R (2000) Dental services, costs, and factors associated with hospitalization for Medicaideligible children, Louisiana 1996-1997. J Public Health Dent 60(3): 2127.

8. Edelstein BL, Reisine S (2015) Fifty-one million: A mythical number that matters. J Am Dent Assoc 146(8): 565-566.

9. Blumenshine SL, Vann WF, Gizlice Z, Lee JY (2008) Children's school performance: Impact of general and oral health. J Public Health Dent 68(2): 82-87.

10. Filstrup SL, Briskie D, daFonseca M, Lawrence L, Wandera A, et al. (2003) The effects on early childhood caries (ECC) and restorative treatment on children's oral health-related quality of life (OHRQOL). Pediatr Dent 25(5): 431-440.

11. O'Sullivan DM, Tinanoff N (1996) The association of early dental caries patterns with caries incidence in preschool children. J Public Health Dent 56(2): 81-83.

12. Drury TF, Horowitz AM, Ismail AI, Maertens MP, Rozier RG, et al. (1999) Diagnosing and reporting early childhood caries for research purposes. J Public Health Dent 59(3): 192-197.

13. Mobley C, Marshall TA, Milgrom P, Coldwell SE (2009) The contribution of dietary factors to dental caries and disparities in caries. Acad Pediatr 9(6): 410-414.

14. Edelstein BL, Chinn CH (2009) Update on disparities in oral health and access to dental care for America's children. Acad Pediatr 9(6): 415-419.

15. Ghazal TSA (2013) Prevalence, Incidence and Risk Factors for Early Childhood Caries Among Young African American Children in Alabama. J Public Health Dent 75(1): 42-48. 
16. Kumar VD (2010) Early childhood caries - an insight. J Int Oral Health 2(1): 1-9.

17. Ribeiro NM, Ribeiro MA (2004) Breastfeeding and early childhood caries: a critical review. J Pediatr 80(5): 199-210.

18. Shahim FN (2003) Factors of risk ealey childhood caries in a selected district in Sri Lanka. Colombo, Sri Lanka: University of Colombo.

19. Low W, Tan S, Schwartz S (1998) The effect of severe caries on the quality of life in young children. Pediatr Dent 21(6): 325-326.

20. National Institute of Dental and Craniofacial Research. Dental caries (tooth decay) in children (Age 2 to 11).

21. Saleem U, Bibi S, Jamil B (2015) Early childhood caries and its relationship with different risk factors in preschool children. J Postgrad Med Inst 29(1): 24-27.

22. Dawani N, Nisar N, Khan N, Syed S, Tanweer N (2012) Prevalence and factors related to dental caries among pre-school children of Saddar town, Karachi, Pakistan: a cross-sectional study. BMC Oral Health 12(1): 59.

23. (2015) American Academy of Pediatric Dentistry. Policy on the dental home. Pediatr Dent 37(special issue): 24-25.

24. Gaffield ML, Gilbert BJ, Malvitz DM (2001) Oral health during pregnancy: An analysis of information collected by the pregnancy risk assessment monitoring system. J Am Dent Assoc132(7): 1009-1016.

25. Huebner CE, Milgrom P, Conrad D, Lee RS (2009) Providing dental care to pregnant patients: A survey of Oregon general dentists. J Am Dent Assoc140(2): 211-222.

26. Keirse MJ, Plutzer K (2010) Women's attitudes to and perceptions of oral health and dental care during pregnancy. J Perinat Med 38(1): 3-8.

27. Kerpen SJ, Burakoff R (2009) Improving access to oral health care for pregnant women. A private practice models. NY State J75(6): 34-36.

28. Dimitrova MM (2009) A study of pregnant women's knowledge of children's feeding practice as a risk factor for early childhood caries. Folia Med (Plovdiv) 51(4): 40-45.

29. Fadavi S, Sevandal MC, Koerber A, Punwani I (2009) Survey of oral health knowledge and behavior of pregnant minority adolescents. Pediatr Dent 31(5): 405-408.

30. Lucey SM (2009) Oral health promotion initiated during pregnancy successful in reducing early childhood caries. Evid Based Dent 10(4): 100-101.

31. Meyer K, Geurtsen W, Gunay H (2010) An early oral health care program starting during pregnancy: Results of a prospective clinical long-term study. Clin Oral Investig 14(3): 257-264.
32. Plutzer K, Spencer AJ (2008) Efficacy of an oral health promotion intervention in the prevention of early childhood caries. Community Dent Oral Epidemiol 36(4): 335-346.

33. (2016) American Academy of Pediatric Dentistry. Guideline on periodicity of examination, preventive dental services, anticipatory guidance/counseling, and oral treatment for infants, children, and adolescents. Pediatr Dent 38(special issue): 132-141.

34. Sinner B, Beck K, Engelhard K (2014) General anesthetics and the developing brain: An overview. Anesthesia 69(9): 1009-1022.

35. Berkowitz RJ, Amante A, Kopycka Kedzierawski DT, Billings RJ, Feng C (2011) Dental caries recurrence following clinical treatment for severe early childhood caries. Pediatr Dent 33(7): 510-514.

36. Edelstein BL, Ng MW (2015) Chronic disease management strategies of early childhood caries: Support from the medical and dental literature. Pediatric Dentistry 37(3): 281-287.

37. (2016) American Academy of Pediatric Dentistry. Guideline on cariesrisk assessment and management for infants, children, and adolescents. Pediatr Dent 38(special issue): 142-149.

38. (2016) American Academy of Pediatric Dentistry. Policy on interim therapeutic restorations (ITR). Pediatric Dentisty 38(special issue): 5051.

39. (2012) American Academy of Pediatrics. Policy statement: Breastfeeding and the use of human milk. Pediatrics 129(3): 827-841.

40. Silk H, Douglass AB, Douglass JM, Silk L (2008) Oral health during pregnancy. Am Fam Physician 77(8): 1139-1144.

41. Boggess KA (2008) Society for Maternal-Fetal Medicine Publications Committee. Maternal oral health in pregnancy. Obstet Gynecol 111(4): 976-986.

42. Dela Cruz GG, Rozier RG, Slade G (2004) Dental screening and referral of young children by pediatric primary care providers. Pediatrics 114(5): 642-652.

43. Sachs HC (2013) Committee on Drugs. The transfer of drugs and therapeutics into human breast milk: An update on selected topics. Pediatrics 132(3): 796-809.

44. (2016) American Academy of Pediatric Dentistry. Guideline on management considerations for pediatric oral surgery and oral pathology. Pediatr Dent 38(special issue): 315-324.

45. Douglass JM, Clark MB (2015) Integrating oral health into overall health care to prevent early childhood caries: Need, evidence, and solutions. Pediatr Dent 37(3): 266-274.

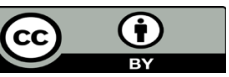

This work is licensed under Creative Commons Attribution 4.0 License

To Submit Your Article Click Here: Submit Article

DOI: $10.32474 /$ IPDOAJ.2019.02.000150

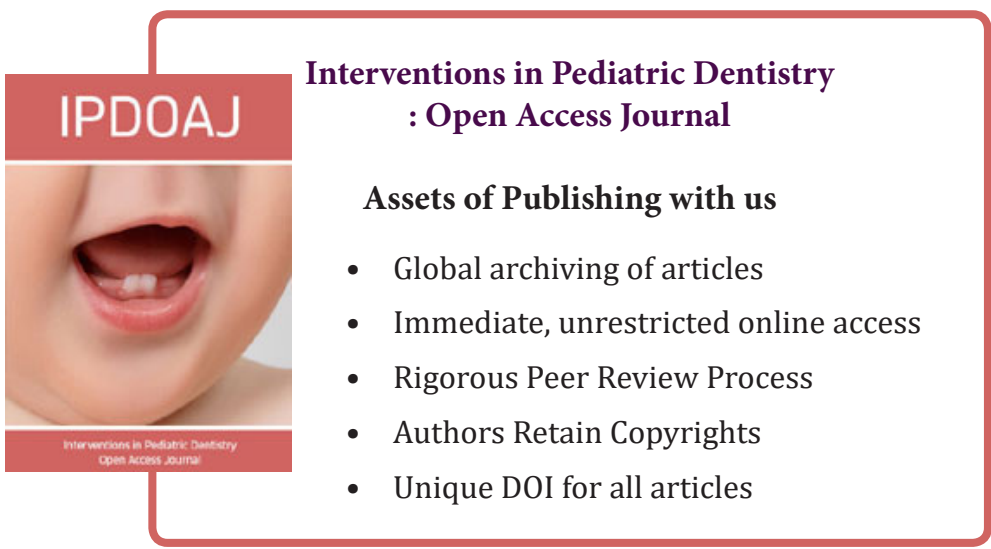

